(2) Open Access Full Text Article

ORIGINALRESEARCH

\title{
Association of Insulin Glargine Treatment with Bone Mineral Density in Patients with Type 2 Diabetes Mellitus
}

\author{
Dan Liu' \\ Jing-Jie $\mathrm{Bai}^{2}$ \\ Jun-Jie Yao' \\ Yong-Bo Wang' \\ Tong Chen' \\ Qian Xing' \\ Ran $\mathrm{Bai}^{\mathrm{I}}$ \\ 'Department of Endocrinology, First \\ Affiliated Hospital of Dalian Medical \\ University, Dalian, Liaoning, People's \\ Republic of China; ${ }^{2}$ Department of \\ Endocrinology, Dalian Children's \\ Hospital, Dalian, Liaoning, People's \\ Republic of China
}

\begin{abstract}
Purpose: To assess the association of type 2 diabetes mellitus (T2DM) and insulin glargine treatment with bone mineral density (BMD) in Chinese people.

Methods: This retrospective study included 50 subjects with T2DM: 25 received oral glucose-lowering medication (ORL group), and 25 received oral glucose-lowering medication in combination with insulin glargine injection (CGI group). Thirty non-diabetic control subjects were also included. BMD was measured at lumbar vertebrae 1-4 (L1-L4), spine bone mineral density (sBMD) results summary (L2-L4), femoral neck and trochanter by dual-energy x-ray absorptiometry.
\end{abstract}

Results: Compared with non-diabetic controls, people with T2DM had significantly lower mean BMD at L2 $(1.073 \pm 0.120$ vs $0.984 \pm 0.158)$, L3 (1.094 \pm 0.129 vs $0.991 \pm 0.163)$ and L4 $(1.089 \pm 0.130$ vs $0.982 \pm 0.165)$ (all $\mathrm{P}<0.05)$, significantly lower levels of serum calcium $(2.02$ \pm 0.22 vs $2.27 \pm 0.17 \mathrm{mmol} / \mathrm{L}, \mathrm{P}<0.05)$, PTH $(24.19 \pm 9.71$ vs $31.52 \pm 8.96 \mathrm{pg} / \mathrm{mL}, \mathrm{P}<0.05)$, and higher serum phosphate levels $(1.43 \pm 0.37$ vs $1.20 \pm 0.15 \mathrm{mmol} / \mathrm{L}, \mathrm{P}<0.05)$. The CGI group had higher L2, L3 and L4 BMD and sBMD (L2-L4) $(\mathrm{P}<0.05)$, higher serum calcium levels $(2.19 \pm 0.11$ vs $1.98 \pm 0.20 \mathrm{mmol} / \mathrm{L}, \mathrm{P}<0.05)$ and lower serum phosphate levels $(1.28 \pm 0.20 \mathrm{vs}$ $1.58 \pm 0.43 \mathrm{mmol} / \mathrm{L}, \mathrm{P}<0.05)$ versus the $\mathrm{ORL}$ group. $\mathrm{BMD}$ and serum calcium levels were associated with the application of insulin glargine.

Conclusion: These results suggest that insulin glargine may affect bone metabolism in patients diagnosed with T2DM. The study has implications for the selection of hypoglycemic agents for diabetic patients at risk of osteoporosis.

Keywords: type 2 diabetes mellitus, insulin glargine, osteoporosis, bone mineral density

\section{Introduction}

The incidence and prevalence of diabetes mellitus (DM) are rapidly rising globally. ${ }^{1}$ As a consequence, DM and its complications have become major issues that threaten human health and contribute towards increasing healthcare costs. ${ }^{2,3}$ Osteoporosis diabetes-induced is a systemic metabolic bone disease characterized by a reduction in bone mineral density (BMD), changes in bone tissue microstructure, decreased bone strength and increased bone fragility, resulting in an increased risk of bone fracture, which is the major skeletal complication of DM. ${ }^{4}$ In particular, for elderly people with DM, hip fractures are associated with increased mortality compared with non-diabetic people of the same age. ${ }^{5}$

Metabolic disturbances related to $\mathrm{DM}$ are associated with a reduction in bone mineral content (BMC), ${ }^{6,7}$ and hyperglycemia is directly involved in the occurrence
Correspondence: Dan Liu; Ran Bai Department of Endocrinology, First Affiliated Hospital of Dalian Medica University, Zhongshan Str.222, Dalian, I I60II, People's Republic of China Email liudandan303114@163.com; bairan5556@I63.com 
of osteoporosis diabetes-induced. ${ }^{89}$ It is widely accepted that type 1 diabetes mellitus (T1DM) can cause osteoporosis, ${ }^{10,11}$ and that this effect is due to the lack of endogenous insulin production in people with T1DM, which diminishes bone turnover. ${ }^{12}$ In contrast, bone metabolism in type 2 diabetes mellitus (T2DM) remains somewhat controversial, with studies variously reporting increased, reduced or unchanged BMD..$^{9,13,14}$ A 2012 meta-analysis reported increased BMD among people with T2DM versus non-diabetic people, although there was great variability between the individual studies included in this analysis. ${ }^{15}$ The discrepancies in the association between T2DM and BMD may be due to differences in the sites used for BMD measurement, selection of subjects, and the complex pathogenesis of osteoporosis diabetes-induced which can be affected by many factors. Furthermore, the increased risk of fracture for people with T2DM is widely accepted, ${ }^{4}$ but the mechanism of this in the context of BMD is not well understood. Despite this uncertainty, possible mechanisms for the effect of T2DM on BMD include the toxic effects of hyperglycemia which may attenuate differentiation and proliferation of osteoblasts. ${ }^{9,16}$ In addition, hyperglycemia can increase urine calcium excretion, which inhibits bone formation. ${ }^{17,18}$ Further possible mechanisms linking T2DM and BMD include the accumulation of advanced glycation end products, which contributes to increased fragility of diabetic bones, ${ }^{19}$ and T2DM-related hypoparathyroidism which may also play a role in the increased risk of fractures. ${ }^{20}$

Insulin glargine is a long-acting basal insulin analogue, used once daily to control glucose levels in $\mathrm{T}_{2} \mathrm{DM}^{21}$ It consists of microcrystals that slowly release insulin, providing a long action without a peak action profile. It is often used in combination with short-acting drugs, such as sulfonylurea and fast acting insulin, to achieve glycemic control. ${ }^{22}$ Data on the relationship between treatment with insulin glargine and BMD in Chinese T2DM patients have not been previously reported. A study of the relatively more rapid-acting insulin lispro protamine in Chinese people with newly-diagnosed T2DM found no effect of insulin treatment on BMD. ${ }^{23}$ Nonetheless, given the role of insulin in bone metabolism, and the importance of fracture risk in people with T2DM, the association of insulin glargine with BMD is an important topic for investigation.

The aim of the present study was to investigate the association of T2DM and treatment with insulin glargine on BMD in Chinese people. In addition, we explored a better understanding of some factors may help improve osteoporosis control in Chinese people with T2DM and prevent fractures.

\section{Subjects, Materials and Methods Subjects}

This was a retrospective study conducted at one study site in China. A total of 50 patients (DM group) with T2DM hospitalized in the Department of Endocrinology, First Affiliated Hospital of Dalian Medical University, from March 2012 to January 2013, were included. All cases were diagnosed according to the 1999 WHO guidelines. Inclusion criteria were: 1) aged 30-60 years; 2) BMI $22-35 \mathrm{~kg} / \mathrm{m}^{2}$; 3) for women: pre-menopausal, and 4) received related therapy for more than 1 year.

Exclusion criteria were: 1) T1DM or other types of DM; 2) acute complications or comorbidities of DM, such as diabetic ketosis or ketoacidosis and hyperosmolar coma, or chronic complications of DM such as diabetic peripheral neuropathy, diabetic retinopathy and diabetic nephropathy; 3) coronary heart disease, cardiac insufficiency, liver and renal dysfunction, other chronic diseases that may affect glucose metabolism; 4) diseases that apparently affect metabolism, such as hyperthyroidism, hypothyroidism, hypercortisolism, hypopituitarism and cancer metastasis to bone; 5) glucocorticoid treatment, hormone replacement therapy or administration of vitamin $D$ and calcium agents that affect bone metabolism; 6) pregnant women, lactating women, women planning for pregnancy, menopausal woman, and those with a history of long-term stay in bed; 7) daily intake of $>60 \mathrm{~g}$ of alcohol for over 5 years; 8 ) smokers with an accumulation of $>500$ cigarettes; 9) osteoporosis and clinical manifestations of osteoporosis.

This retrospective study was approved by the ethics committee of the First Affiliated Hospital of Dalian Medical University and written informed consent was obtained from all participants. The study was conducted in accordance with the principles of good clinical practice and the declaration of Helsinki 1964 and its subsequent amendments.

\section{Therapies}

Subjects in the DM group were divided by those who received oral glucose-lowering medication (ORL group, $n=25$ ) or oral glucose-lowering medication in combination with insulin glargine injection (CGI group, $\mathrm{n}=25$ ). In addition, 30 non-diabetic subjects were included as a control group. Patients in the ORL group received glimepiride (Sanofi, Paris, France) 2 mg QD PO, metformin hydrochloride (Bristol-Meyer Squibb, 
New York, NY, USA) 500 mg TID PO and/or acarbose (Bayer HealthCare Pharmaceuticals, Montville, NJ, USA) $50 \mathrm{mg}$ TID PO. Two people in the ORL group took acarbose, and four people in the CGI group took acarbose. Patients in the CGI group received the same hypoglycemic agents as the ORL group in addition to insulin glargine (Lantus, 300U, Sanofi, Paris, France) $17.76 \pm 3.28 \mathrm{U}$ per day. All the enrolled participants maintained a diabetic diet, and their physical activities were routine exercises due to lack of knowledge about the prevention of osteoporosis.

\section{Measurement of BMD}

The BMD at lumbar vertebrae 1-4 (L1-L4), spine bone mineral density (sBMD) results summary (L2-L4), femoral neck and trochanter was measured using dual-energy x-ray absorptiometry (Hologic, Inc., Bedford, MA, USA), and $\mathrm{BMD}$ was calculated as the BMC divided by projected bone area. Study participants' BMD was compared with reference BMD values from young non-diabetic subjects ( $T$ value) and with non-diabetic subjects from the same age group ( $\mathrm{Z}$ value).

\section{Determination of Blood Biochemical Parameters}

Serum levels of calcium, phosphate, total cholesterol (TC), alkaline phosphatase (ALP), alanine aminotransferase (ALT), aspartate aminotransferase (AST), creatinine, uric acid (UA), and fasting plasma glucose (FPG) were determined using a Hitachi 7180 biochemistry automatic analyzer (Hitachi, Tokyo, Japan).

Serum glycosylated hemoglobin A1c (HbA1c) levels were determined by immunoturbidimetry. All measurements were performed in the Department of Laboratory Medicine of the First Affiliated Hospital of Dalian Medical University (Dalian, China).

\section{Measurement of Calcitonin and Parathyroid Hormone Levels}

Parathyroid hormone (PTH) was measured using a doubleantibody sandwich assay with a Roche 411 immunoassay analyzer (Roche Diagnostics, Basel, Switzerland). Calcitonin (CT) levels were determined using a solid-phase sandwich enzyme-linked immunosorbent assay (ELISA, Siemens Healthcare Diagnostics Inc., Erlangen, Germany).

\section{Statistical Analysis}

All statistical analyses were performed using SPSS 17.0 (SPSS Inc., Chicago, IL, USA). Continuous data are expressed as mean \pm standard deviation (SD). Normally distributed variables were compared using one-way analysis of variance (ANOVA). Non-normally distributed variable that became normally distributed after log transformation was compared using ANOVA; otherwise, the nonparametric rank sum test was used. A $P$-value $<0.05$ was considered statistically significant.

To identify insulin glargine associated with BMD, binary logistic regression analysis was performed using ORL group and CGI group as dependent variables, when oneway ANOVA was used, the indicators with statistical differences between ORL group and CGI group were sBMD (L2-L4) and clinical characteristics including serum $\mathrm{Ca}$, serum P, ALT, AST as independent variables.

\section{Results \\ Baseline Characteristics}

Baseline clinical characteristics and bone indices are summarized in Table 1. The patients in the ORL group (17 male and eight female) had a mean age of $44.4 \pm 8.13$ years, and a mean disease duration of $5.0 \pm 3.16$ years. The subjects in the CGI group (18 male and seven female) had a mean age of $42.60 \pm 9.25$ years and a mean disease duration of $6.5 \pm 3.36$ years. The control group included 20 men and 10 women, with a mean age of $42.4 \pm 6.71$ years. Higher FPG and HbA1c levels were observed in the DM group compared with the control group $(P<0.001)$, while no significant differences were observed in gender, age, BMI, and serum levels of TC, ALP, AST, ALT, and creatinine (all $P>0.05$ ).

There were no significant differences in gender, age, disease duration, BMI, SBP, DBP, and levels of FPG, HbA1c, TC and ALP between the ORL and CGI groups (all $P>0.05$ ). Significant differences were observed in AST (18.44 \pm 6.21 vs $26.60 \pm 11.93 \mathrm{P}=0.04)$ and ALT $(25.32 \pm 12.19$ vs $44.60 \pm 28.54 ; \mathrm{P}=0.01$ ) levels between the ORL and CGI groups; however, all AST and ALT levels were lower than $80 \mathrm{U} / \mathrm{L}$, indicating no liver injury (Table 1).

\section{Comparison of BMD Between the DM and Control Groups, and Between the ORL and CGI Groups}

As shown in Table 2, lower BMD at L2-L4 was measured in the DM group compared with controls $(P=0.01,0.04$ and 0.04 , respectively). In contrast, no significant differences were measured in the BMD at L1, femoral neck and the greater trochanter between the DM and control groups (all $P>0.05$ ). 
Table I Baseline Characteristics of Study Participants

\begin{tabular}{|c|c|c|c|c|}
\hline \multirow[t]{2}{*}{ Parameters $^{\mathbf{a}}$} & Control Group & ORL Group & CGI Group & $\begin{array}{c}\text { Combined DM } \\
\text { Group }\end{array}$ \\
\hline & $n=30$ & $n=25$ & $n=25$ & $n=50$ \\
\hline Male/female $(n / n)$ & $20 / 10$ & $17 / 8$ & $18 / 7$ & $35 / 15$ \\
\hline Age (years) & $42.34 \pm 6.71$ & $44.44 \pm 8.13$ & $42.60 \pm 9.25$ & $43.47 \pm 9.37$ \\
\hline Disease duration (years) & - & $5.010 \pm 3.16$ & $6.52 \pm 3.36$ & $5.91 \pm 3.39$ \\
\hline BMI $\left(\mathrm{kg} / \mathrm{m}^{2}\right)$ & $24.77 \pm 2.52$ & $27.76 \pm 7.21$ & $27.79 \pm 3.89$ & $27.78 \pm 5.73$ \\
\hline ALP $(U / L)$ & $51.80 \pm 15.07$ & $68.08 \pm 25.55$ & $50.96 \pm 15.67$ & $59.52 \pm 22.69$ \\
\hline ALT (U/L) & $22.10 \pm 11.14$ & $25.32 \pm 12.19$ & $44.60 \pm 28.54 *$ & $34.96 \pm 23.80$ \\
\hline AST (U/L) & $22.60 \pm 8.42$ & $\mid 8.44 \pm 6.21$ & $26.60 \pm 11.93 *$ & $22.52 \pm 10.28$ \\
\hline FPG (mmol/L) & $5.20 \pm 0.44$ & $10.53 \pm 2.04^{\#}$ & $10.41 \pm 2.76^{\#}$ & $10.47 \pm 2.4 I^{\#}$ \\
\hline HbAlc (\%) & $5.05 \pm 0.491$ & $8.84 \pm 1.78^{\#}$ & $8.59 \pm 1.67^{\#}$ & $8.7| \pm I .7|^{\#}$ \\
\hline $\mathrm{TC}(\mathrm{mmol} / \mathrm{L})$ & $181.43 \pm 32.93$ & $170.44 \pm 49.69$ & $170.64 \pm 34.62$ & $170.54 \pm 42.38$ \\
\hline
\end{tabular}

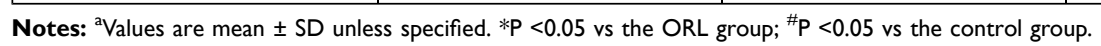

Abbreviations: ORL, oral glucose-lowering medication; CGI, oral glucose-lowering medication in combination with insulin glargine injection; DM, diabetes mellitus; BMI, body mass index; ALP, alkaline phosphatase; ALT, alanine aminotransferase; AST, aspartate aminotransferase; FPG, fasting plasma glucose; HbAIc, glycosylated hemoglobin Alc; TC, total cholesterol.

Interestingly, the BMD at L2-L4 and sBMD (L2-L4) was significantly higher in the CGI group than in the ORL group $(P=0.025,0.041,0.025$ and 0.015 , respectively). There were no significant differences in the BMD at L1, femoral neck and the greater trochanter between the CGI and ORL groups $(P>0.05)$; however, a tendency toward higher values in the CGI group was observed (Table 2).
Comparison of Bone Metabolism Indices Between the DM and Control Groups, and Between the ORL and CGI Groups

Subjects in the DM group had significantly lower serum calcium $(2.02 \pm 0.22$ vs $2.27 \pm 0.17 \mathrm{mmol} / \mathrm{L}, \mathrm{P}=0.001)$ and PTH levels (24.19 \pm 9.71 vs $31.52 \pm 8.96 \mathrm{pg} / \mathrm{mL} ; \mathrm{P}=0.01)$ and higher phosphate $(1.43 \pm 0.37$ vs $1.20 \pm 0.15 \mathrm{mmol} / \mathrm{L}$;

Table 2 BMD According to T2DM and Treatment Status

\begin{tabular}{|l|c|c|c|c|}
\hline \multirow{2}{*}{ Site } & Control Group & ORL Group & CGI Group & Combined DM Group \\
\cline { 2 - 5 } & $\mathbf{n = 3 0}$ & $\mathbf{n = 2 5}\left(\mathbf{g} / \mathrm{cm}^{2}\right)^{\mathbf{a}}$ & $\mathbf{n = 5 0}$ \\
\hline LI & $1.036 \pm 0.124$ & $0.934 \pm 0.110$ & $0.994 \pm 0.107$ & $0.957 \pm 0.132$ \\
\hline L2 & $1.073 \pm 0.120$ & $0.951 \pm 0.127$ & $1.038 \pm 0.13 I^{*}$ & $0.984 \pm 0.158^{\#}$ \\
\hline L3 & $1.094 \pm 0.129$ & $0.956 \pm 0.136$ & $1.041 \pm 0.140^{*}$ & $0.991 \pm 0.163^{\#}$ \\
\hline L4 & $1.089 \pm 0.130$ & $0.944 \pm 0.137$ & $1.039 \pm 0.146^{*}$ & $0.982 \pm 0.165^{\#}$ \\
\hline L2-L4 & $1.080 \pm 0.122$ & $1.055 \pm 0.081$ & $1.154 \pm 0.125^{*}$ & $1.104 \pm 0.115$ \\
\hline Femoral neck & $0.857 \pm 0.103$ & $0.856 \pm 0.067$ & $0.902 \pm 0.163$ & $0.881 \pm 0.156$ \\
\hline Trochanter & $0.749 \pm 0.107$ & $0.761 \pm 0.120$ & $0.828 \pm 0.178$ & $0.804 \pm 0.163$ \\
\hline
\end{tabular}

Notes: ${ }^{a}$ Values are mean \pm SD unless specified. ${ }^{*} \mathrm{P}<0.05$ vs the $O R L$ group; ${ }^{\#} \mathrm{P}<0.05$ vs the control group.

Abbreviations: ORL, oral glucose-lowering medication; CGI, oral glucose-lowering medication in combination with insulin glargine injection; DM, diabetes mellitus; BMD, bone mineral density. 
Table 3 Bone Metabolism Indices According to T2DM and Treatment Status

\begin{tabular}{|l|c|c|c|c|}
\hline Metabolic Indexes $^{\mathbf{a}}$ & Control Group & ORL Group & CGI Group & $\begin{array}{c}\text { Combined DM } \\
\text { Group }\end{array}$ \\
\cline { 2 - 5 } & $\mathbf{n = 3 0}$ & $\mathbf{n = 2 5}$ & $\mathbf{n = 2 5}$ & $55.72 \pm 14.02$ \\
\hline Serum Cre $(\mu \mathrm{mol} / \mathrm{L})$ & $62.27 \pm 10.83$ & $51.92 \pm 10.64$ & $59.52 \pm 16.07$ & $2.02 \pm 0.22^{\#}$ \\
\hline Serum Ca $(\mathrm{mmol} / \mathrm{L})$ & $2.27 \pm 0.17$ & $1.98 \pm 0.20$ & $2.19 \pm 0.11^{*}$ & $1.43 \pm 0.37^{\#}$ \\
\hline Serum P $(\mathrm{mmol} / \mathrm{L})$ & $1.20 \pm 0.15$ & $1.58 \pm 0.43$ & $21.75 \pm 10.4$ & $24.19 \pm 9.7 I^{\#}$ \\
\hline PTH $(\mathrm{pg} / \mathrm{mL})$ & $31.52 \pm 8.96$ & $26.64 \pm 8.46$ & $0.73 \pm 1.44$ & $0.61 \pm 1.32$ \\
\hline CT $(\mathrm{ng} / \mathrm{mL})$ & - & $0.49 \pm 1.30$ & & \\
\hline
\end{tabular}

Notes: ${ }^{a}$ Values are mean \pm SD unless specified. $* \mathrm{P}<0.05$ vs the $\mathrm{ORL}$ group; ${ }^{\#} \mathrm{P}<0.05$ vs the control group.

Abbreviations: ORL, oral glucose-lowering medication; CGl, oral glucose-lowering medication in combination with insulin glargine injection; DM, diabetes mellitus; serum Cre, serum creatinine; Serum Ca, serum calcium; Serum P, serum phosphate; PTH, parathyroid hormone; CT, calcitonin.

$\mathrm{P}=0.001$ ) levels, compared with non-diabetic control subjects (Table 3).

Furthermore, significantly higher serum calcium levels (2.17 \pm 0.11 vs $1.98 \pm 0.20 \mathrm{mmol} / \mathrm{L} ; \mathrm{P}<0.001)$ and lower serum phosphate levels $(1.28 \pm 0.20$ vs $1.58 \pm 0.43 \mathrm{mmol} / \mathrm{L}, \mathrm{P}=0.04)$ were found in the CGI group compared with the ORL group, while no significant differences were found in the PTH and CT levels between the two groups $(P>0.05)$ (Table 3$)$.

\section{Association Between BMD and Clinical Characteristics with Insulin Glargine}

sBMD (L2-L4) and serum Ca showed a positive correlation with insulin glargine, in addition, serum $\mathrm{Ca}$, serum $\mathrm{P}, \mathrm{ALT}$, AST were not associated with insulin glargine (Table 4).

\section{Discussion}

Osteoporosis and bone fractures affect many people with DM. ${ }^{24}$ With the prolongation of life expectancy for people with DM, and therefore of the disease duration, there has been a gradual increase in the incidence of osteoporosis diabetes-induced in patients with $\mathrm{DM}^{25}$ and the

Table 4 Binary Logistic Regression Analysis of Related Indicators

\begin{tabular}{|l|c|c|c|c|c|}
\hline & B & S.E. & Wald & Sig. & Exp(B) \\
\hline sBMD(L2-L4) & 0.011 & 0.005 & 4.892 & 0.027 & 1.011 \\
\hline Serum Ca & 0.446 & 0.185 & 5.831 & 0.016 & 1.563 \\
\hline Serum P & 0.082 & 1.594 & 0.003 & 0.959 & 1.085 \\
\hline ALT & -0.857 & 0.954 & 0.806 & 0.369 & 0.425 \\
\hline AST & 1.214 & 1.290 & 0.885 & 0.347 & 3.366 \\
\hline
\end{tabular}

Abbreviations: BMD, bone mineral density; Serum $C a$, serum calcium; Serum $P$, serum phosphate; ALT, alanine aminotransferase; AST, aspartate aminotransferase. prevalence of both DM and osteoporosis is increasing. Therefore, the relationship between DM and osteoporosis warrant attention. In this regard, the present study found lower BMD at L2, L3 and L4 as well as lower serum calcium and PTH levels and higher serum phosphate levels in individuals with T2DM compared with non-diabetic controls. This study also found that people with T2DM who received insulin glargine had a significantly higher sBMD (L2-L4) compared with those receiving oral antidiabetic medication only, as well as higher serum calcium levels and lower serum phosphate levels.

In the present study, significant differences in BMD at L2, L3 and L4 between individuals with T2DM and nondiabetic subjects were observed, while no significant differences were detected in the femoral neck and great trochanter. This is in contrast with a previous analysis based on the Rotterdam study which showed higher BMD at the femoral neck and lumbar spine in people with T2DM compared with non-diabetic individuals, and also a previous meta-analysis which found higher BMD in people with T2DM. ${ }^{15,26}$ Although it should be noted that several smaller studies have shown lower BMD in patients with T2DM. ${ }^{27}$ The contrasting results of the present study compared with some of the previous findings may be in part due to the characteristics of subjects enrolled in this study, particularly because relatively younger patients and a higher proportion of women were included in the present study versus these previous reports, which is known to influence BMD. In particular, a higher BMD has been observed in older women with T2DM. ${ }^{28}$

In addition, there were significant differences in SBMD (L2-L4) between the CGI and ORL groups, but no significant differences were found in the BMD at femoral 
neck and great trochanter. A significantly higher BMD at lumbar vertebrae was measured in T2DM patients who had received insulin for more than 3 years compared with those receiving oral glucose-lowering drugs alone, suggesting that exogenous insulin is beneficial for osteoporosis in patients with T2DM. ${ }^{16,29}$ Previous studies investigated the changes in BMD at femoral neck in T2DM patients receiving antidiabetic therapy with oral glucose-lowering drugs and insulin, and observed that the addition of exogenous insulin was an important approach for the treatment of DM-induced osteoporosis, increasing BMD and preventing bone loss. ${ }^{16,29-31}$ Our results also show that patients in the CGI group had higher serum calcium levels and lower serum phosphate levels compared with the ORL group, and that their sBMD (L2-L4) was higher, which is consistent with these previous studies. In addition to controlling blood glucose, insulin plays a critical role in maintaining bone mass and preventing bone mass loss. It has been found that decreases in insulin levels, insulin hyposecretion ${ }^{32}$ and insulin resistance ${ }^{32-34}$ may cause osteoporosis. Insulin receptors are present on osteoblasts, and insulin promotes the formation of osteoblast nucleic acid, and protects bone tissues. Insulin also inhibits adenylate cyclase activity; elevated levels of adenylate cyclase promotes bone resorption and increases bone destruction, resulting in osteoporosis. ${ }^{35}$ In addition, insulin may activate 25-hydroxylase, and work with PTH to mediate 1-alpha-hydroxylase activity, which stimulates the production of $1.25-(\mathrm{OH})_{2} \mathrm{D}_{3}$ in the renal proximal tubule and promotes the intestinal absorption of calcium and phosphate. Therefore, insulin may promote an increase in the number and activity of osteoblasts, and accelerate the synthesis of osteocalcin and collagen in osteoblasts. Unfortunately, it has been reported that the use of insulin increases the risk of fractures and does not improve BMD. ${ }^{36-38}$ Also, another study indicated that patients with T2DM treated with insulin alone had a 1.6-fold increase in fracture risk compared with metformin alone. ${ }^{39}$ This may be related to the fact that insulin use may lead to episodes of hypoglycemia and that patients treated with insulin are at greater risk for other complications. ${ }^{40}$ Overall, it is important to note that the impact on bone metabolism and the risk of fractures need to be assessed before the application of insulin to treat DM.

In addition, Kanazawa et al found that in patients with T2DM treated with insulin, the risk of fracture is significantly increased in men compared women. ${ }^{41}$ Another study showed that no difference in BMD among women with T2DM who received diet, oral hypoglycemic drugs, or insulin, while men with T2DM who received insulin had lower BMD than those who received other treatments. ${ }^{42}$ It is unclear whether the effect of At present, there are few studies on the risk of osteoporosis and fractures by gender of patients with T2DM, and it is unclear whether the effect of hypoglycemic drugs on bone varies by gender. ${ }^{43}$ Consequently, the impact on gender differences on the BMD and fracture risk of T2DM patients treated with hypoglycemic drugs needs to be further explored.

Some other factors may also affect BMD of patients with T2DM. It is widely accepted that the risk of osteoporosis increases with the prolongation of DM disease duration. BMD was reduced with the prolongation of DM duration, which is supported by several previous studies. $^{8,9}$ The pathological changes which accompany DM cause reductions in bone collagen, decreased bone matrix maturation and conversion, and calcium loss, resulting in decreased BMD. ${ }^{8,9}$ Moreover, longer diabetes duration has been observed to increase the risk of fracture. ${ }^{44}$ In addition, microvascular complications occur in DM with the prolongation of the disease duration, which affects the vascular distribution, and the increased capillary permeability may cause a reduction of BMD. ${ }^{45}$ But, in 2020, a study found that there was no correlation between the duration of DM and BMD of lumbar spine in T2DM patients. ${ }^{46}$

It is well known that patients with T2DM have higher HBA1c than non-diabetics. HbA1c is not significantly associated with BMD of lumbar in patients with T2DM, according to a new study. ${ }^{46}$ However, the incidence of hip fracture was positively correlated with HBA1c. ${ }^{47}$ Whether HBA1c is related to BMD or fracture risk needs further verified.

Body weight has also been associated with $\mathrm{BMD} ;{ }^{48}$ in adults without diseases that affect bone metabolism, the detection of osteoporosis and the risk of non-vertebral fractures decrease with increased BMI. ${ }^{49}$ However, in the present study, BMI only showed an association with BMD at L4 for T2DM patients who received oral anti-hyperglycemic medication. Finally, BMD has been demonstrated to decrease with increasing age. ${ }^{50,51}$ Tang et al reported in detail that in Chinese people with T2DM, total BMD male patients is not related to age, while BMD at lumbar spine is positively correlated with age, and BMD at femoral neck is negatively correlated with age. The BMD of all 
parts in female patients is negatively correlated with age. ${ }^{52}$ BMD of femoral neck and total hip tended to decrease with age, consistent with the findings of Jiang et al, who also found that BMD at lumbar spine was not related to age. $^{53,54}$

In addition, it is worth mentioning that although BMD has an effect in assessing the risk of osteoporosis or fractures, but previous studies have found that BMD is not the only predictor of fracture risk. Phalangeal quantitative ultrasound, bone material strength index, trabecular bone score and serum levels of fibroblast factor 21 can also identify fracture risk. ${ }^{55-57}$ Therefore, in addition to $\mathrm{BMD}$, there are more indicators for predicting fracture risk that deserve attention.

The present study has several limitations which warrant discussion. Firstly, the relatively small sample size and short follow-up precluded observation of longitudinal changes in BMD. Secondly, for the treated patients there were no baseline data to allow paired analysis of treatment effect. Further studies with a larger sample size and longer follow-up are required to evaluate the effect of insulin glargine on BMD and bone metabolism in patients with T2DM. Lastly, although the enrolled patients were consistent with no previous fracture history and no bone and joint pain characteristics on physical examination, the lack of bone imaging information such as X-ray was a limitation of this study. Despite these limitations, the study did have strengths including using strict selection criteria, and in order to avoid the effect of gonadal hormone on BMD, the range of age was from 30 to 60 years, especially for pre-menopausal women. In addition to the above-mentioned strengths, from the perspective of the treatment of diabetic patients, insulin glargine is a longacting insulin that can target the decline of pancreatic islet function in Asian populations ${ }^{58}$ and change the current status of hypoglycemic treatment, and the effect on BMD is to explore the protective effect in addition to hypoglycemic effect.

In conclusion, for Chinese people with T2DM, the present study suggests that insulin glargine may affect bone metabolism in patients diagnosed with T2DM, thus providing a reference for the selection of hypoglycemic agents in diabetic patients at risk of osteoporosis. To the best of our knowledge, this study is also the first report to describe a beneficial effect of insulin glargine on BMD in patients with T2DM. In view of the beneficial effect of exogenous insulin on BMD in this study, the mechanism of effect of exogenous insulin on BMD needs to be further studied. Whether clinicians should give priority to exogenous insulin therapy when formulating a hypoglycemic plan for people with diabetes who are predisposed to osteoporosis is a question worthy of further discussion.

\section{Ethical Approval}

This retrospective study was approved by the ethics committee of the First Affiliated Hospital of Dalian Medical University.

\section{Acknowledgment}

Editorial support for this manuscript was paid for by Sanofi and provided by Adelphi.

\section{Disclosure}

The authors report no conflicts of interest for this work.

\section{References}

1. Avdicova M, Aris T, Sakarya S. Worldwide trends in diabetes since 1980: a pooled analysis of 751 population-based studies with 4.4 million participants. Lancet. 2016;387(10027):1513-1530. doi:10.1016/S0140-6736(16)00618-8

2. Hsu JY, Cheng CY, Hsu CY. Type 2 diabetes mellitus severity correlates with risk of hip fracture in patients with osteoporosis. Neth J Med. 2018;76(2):65-71.

3. Zhang P, Zhang X, Brown J, et al. Global healthcare expenditure on diabetes for 2010 and 2030. Diabetes Res Clin Pract. 2010;87 (3):293-301. doi:10.1016/j.diabres.2010.01.026

4. Oei L, Zillikens MC, Dehghan A, et al. High bone mineral density and fracture risk in type 2 diabetes as skeletal complications of inadequate glucose control: the Rotterdam Study. Diabetes Care. 2013;36(6):1619-1628. doi:10.2337/dc12-1188

5. Gulcelik NE, Bayraktar M, Caglar O, Alpaslan M, Karakaya J. Mortality after hip fracture in diabetic patients. Exp Clin Endocrinol Diabetes. 2011;119(7):414-418. doi:10.1055/s-00301270466

6. Lewis R. Mineral and bone disorders in chronic kidney disease: new insights into mechanism and management. Ann Clin Biochem. 2012;49(Pt 5):432-440. doi:10.1258/acb.2012.012004

7. Olmos JM, Pérez-Castrillón JL, García MT, et al. Bone densitometry and biochemical bone remodeling markers in type 1 diabetes mellitus. Bone Miner. 1994;26(1):1-8. doi:10.1016/s0169-6009(08) 80157-2

8. Kanazawa I, Yamaguchi T, Yamamoto M, et al. Combination of obesity with hyperglycemia is a risk factor for the presence of vertebral fractures in type 2 diabetic men. Calcif Tissue Int. 2008;83(5):324-331. doi:10.1007/s00223-008-9178-6

9. Schwartz AV, Sellmeyer DE, Strotmeyer ES, et al. Diabetes and bone loss at the hip in older black and white adults. $J$ Bone Mineral Res. 2005;20(4):596-603. doi:10.1359/JBMR.041219

10. Kemink SA, Hermus AR, Swinkels LM, Lutterman JA, Smals AG. Osteopenia in insulin-dependent diabetes mellitus; prevalence and aspects of pathophysiology. $J$ Endocrinol Invest. 2000;23 (5):295-303. doi:10.1007/BF03343726

11. Lopez-Ibarra PJ, Pastor MMC, Escobar-Jiménez F, et al. Bone mineral density at time of clinical diagnosis of adult-onset type 1 diabetes mellitus. Endocrine Pract. 2001;7(5):346-351. doi:10.4158/ EP.7.5.346 
12. Jara A, Bover J, Felsenfeld AJ. Development of secondary hyperparathyroidism and bone disease in diabetic rats with renal failure. Kidney Int. 1995;47(6):1746-1751. doi:10.1038/ki.1995.241

13. Dennison EM, Syddall HE, Aihie Sayer A, et al. Type 2 diabetes mellitus is associated with increased axial bone density in men and women from the Hertfordshire Cohort Study: evidence for an indirect effect of insulin resistance? Diabetologia. 2004;47(11):1963-1968. doi:10.1007/s00125-004-1560-y

14. van Daele PL. Bone density in non-insulin-dependent diabetes mellitus. The Rotterdam Study. Ann Intern Med. 1995;122(6):409-414. doi:10.7326/0003-4819-122-6-199503150-00002

15. Ma L, Oei L, Jiang L, et al. Association between bone mineral density and type 2 diabetes mellitus: a meta-analysis of observational studies. Eur J Epidemiol. 2012;27(5):319-332. doi:10.1007/s10654-012-9674-X

16. Thrailkill KM, Lumpkin CK, Bunn RC, Kemp SF, Fowlkes JL. Is insulin an anabolic agent in bone? Dissecting the diabetic bone for clues. Am J Physiol Endocrinol Metab. 2005;289(5):E735-745. doi:10.1152/ajpendo.00159.2005

17. Raskin P, Stevenson MR, Barilla DE, Pak CY. The hypercalciuria of diabetes mellitus: its amelioration with insulin. Clin Endocrinol (Oxf). 1978;9(4):329-335. doi:10.1111/j.1365-2265.1978.tb02218.x

18. Tzamaloukas AH, Ing TS, Siamopoulos KC, et al. Pathophysiology and management of fluid and electrolyte disturbances in patients on chronic dialysis with severe hyperglycemia. Semin Dial. 2008;21 (5):431-439. doi:10.1111/j.1525-139X.2008.00464.x

19. Krakauer JC, Mckenna MJ, Fenn Buderer N, et al. Bone loss and bone turnover in diabetes. Diabetes. 1995;44(7):775-782. doi:10.2337/diab.44.7.775

20. Thalassinos NC, Hadjiyanni P, Tzanela M, Alevizaki C, Philokiprou D. Calcium metabolism in diabetes mellitus: effect of improved blood glucose control. Diabetic Med. 1993;10(4):341-344. doi:10.1111/j.1464-5491.1993.tb00076.x

21. Thisted H, Johnsen SP, Rungby J. An update on the long-acting insulin analogue glargine. Basic Clin Pharmacol Toxicol. 2006;99 (1):1-11. doi:10.1111/j.1742-7843.2006.pto_352.x

22. Bolli GB, Di Marchi RD, Park GD, Pramming S, Koivisto VA. Insulin analogues and their potential in the management of diabetes mellitus. Diabetologia. 1999;42(10):1151-1167. doi:10.1007/s001250051286

23. Li R, Xu W, Luo S, et al. Effect of exenatide, insulin and pioglitazone on bone metabolism in patients with newly diagnosed type 2 diabetes. Acta Diabetol. 2015;52(6):1083-1091. doi:10.1007/ s00592-015-0792-2

24. Moseley KF. Type 2 diabetes and bone fractures. Curr Opin Endocrinol Diabetes Obes. 2012;19(2):128-135. doi:10.1097/ MED.0b013e328350a6e1

25. Hofbauer LC, Brueck CC, Singh SK, Dobnig H. Osteoporosis in patients with diabetes mellitus. J Bone Mineral Res. 2007;22 (9):1317-1328. doi:10.1359/jbmr.070510

26. De L, van der Klift M, de Laet $\mathrm{CEDH}$, et al. Bone mineral density and fracture risk in type-2 diabetes mellitus: the Rotterdam Study. Osteoporosis Int. 2005;16(12):1713-1720. doi:10.1007/s00198-0051909-1

27. Abdulameer SA, Sulaiman SA, Hassali MA, Subramaniam K, Sahib MN. Osteoporosis and type 2 diabetes mellitus: what do we know, and what we can do? Patient Prefer Adherence. 2012;6:435-448. doi:10.2147/PPA.S32745

28. Barrett-Connor E, Holbrook TL. Sex differences in osteoporosis in older adults with non-insulin-dependent diabetes mellitus. JAMA. 1992;268(23):3333-3337. doi:10.1001/jama.1992.03490230063029

29. Campos Pastor MM, Lopez-Ibarra PJ, Escobar-Jimenez F, Serrano Pardo MD, Garcia-Cervigon AG. Intensive insulin therapy and bone mineral density in type 1 diabetes mellitus: a prospective study. Osteoporosis Int. 2000;11(5):455-459. doi:10.1007/s001980070114

30. Diamant M, Heine RJ. Thiazolidinediones in type 2 diabetes mellitus: current clinical evidence. Drugs. 2003;63(13):1373-1405. doi:10.2165/00003495-200363130-00004
31. Lecka-Czernik B. Bone loss in diabetes: use of antidiabetic thiazolidinediones and secondary osteoporosis. Curr Osteoporos Rep. 2010;8 (4):178-184. doi:10.1007/s11914-010-0027-y

32. Gunczler P, Lanes R, Paoli M, et al. Decreased bone mineral density and bone formation markers shortly after diagnosis of clinical type 1 diabetes mellitus. $J$ Pediatric Endocrinol Metab. 2001;14 (5):525-528. doi:10.1515/jpem.2001.14.5.525

33. Hamada Y. [Relationship between insulin resistance and bone metabolism]. Clin Calcium. 2009;19(9):1269-1274. Japanese.

34. Xia J, Zhong Y, Huang G, et al. The relationship between insulin resistance and osteoporosis in elderly male type 2 diabetes mellitus and diabetic nephropathy. Ann d'endocrinologie. 2012;73 (6):546-551. doi:10.1016/j.ando.2012.09.009

35. Zhou Y, Zhu ZL, Guan XX, Hou WW, Yu HY. Reciprocal roles between caffeine and estrogen on bone via differently regulating cAMP/PKA pathway: the possible mechanism for caffeine-induced osteoporosis in women and estrogen's antagonistic effects. Med Hypotheses. 2009;73(1):83-85. doi:10.1016/j.mehy.2009.01.029

36. Stage TB, Christensen M-MH, Jørgensen NR, et al. Effects of metformin, rosiglitazone and insulin on bone metabolism in patients with type 2 diabetes. Bone. 2018;112:35-41. doi:10.1016/j.bone.2018.04.004

37. Ivers RQ, Cumming RG, Mitchell P, Peduto AJ. Diabetes and risk of fracture: the Blue Mountains Eye Study. Diabetes Care. 2001;24 (7):1198-1203. doi:10.2337/diacare.24.7.1198

38. Melton LJ, Leibson CL, Achenbach SJ, Therneau TM, Khosla S. Fracture risk in type 2 diabetes: update of a population-based study. J Bone Miner Res. 2008;23(8):1334-1342. doi:10.1359/jbmr.080323

39. Losada E, Soldevila B, Ali MS, et al. Real-world antidiabetic drug use and fracture risk in 12,277 patients with type 2 diabetes mellitus: a nested case-control study. Osteoporos Int. 2018;29(9):2079-2086. doi:10.1007/s00198-018-4581-y

40. Jackuliak P, Kužma M, Payer J. Effect of antidiabetic treatment on bone. Physiol Res. 2019;68(Suppl 2):S107-s120. doi:10.33549/ physiolres.934297

41. Monami M, Cresci B, Colombini A, et al. Bone fractures and hypoglycemic treatment in type 2 diabetic patients: a case-control study. Diabetes Care. 2008;31(2):199-203. doi:10.2337/dc07-1736

42. Leidig-Bruckner G, Grobholz S, Bruckner T, et al. Prevalence and determinants of osteoporosis in patients with type 1 and type 2 diabetes mellitus. BMC Endocr Disord. 2014;14(1):33. doi:10.1186/1472-682314-33

43. Russo GT, Giandalia A, Romeo EL, et al. Fracture risk in type 2 diabetes: current perspectives and gender differences. Int J Endocrinol. 2016;2016:1615735. doi:10.1155/2016/1615735

44. Compston J. Type 2 diabetes mellitus and bone. J Intern Med. 2018;283(2):140-153. doi:10.1111/joim.12725

45. Leidig-Bruckner G, Ziegler R. Diabetes mellitus a risk for osteoporosis? Exp Clin Endocrinol Diabetes. 2001;109 Suppl 2: S493-514. doi:10.1055/s-2001-18605

46. Yao X, Xu X, Jin F, Zhu Z. The correlation of type 2 diabetes status with bone mineral density in middle-aged adults. Diabetes Metab Syndr Obes. 2020;13:3269-3276. doi:10.2147/dmso.S268592

47. Li C-I, Liu C-S, Lin W-Y, et al. Glycated hemoglobin level and risk of hip fracture in older people with type 2 diabetes: a competing risk analysis of Taiwan Diabetes Cohort Study. J Bone Miner Res. 2015;30(7):1338-1346. doi:10.1002/jbmr.2462

48. Felson DT, Zhang Y, Hannan MT, Anderson JJ. Effects of weight and body mass index on bone mineral density in men and women: the Framingham study. $J$ Bone Mineral Res. 1993;8(5):567-573. doi:10.1002/jbmr.5650080507

49. Rithirangsriroj K, Panyakhamlerd K, Chaikittisilpa S, Chaiwatanarat T, Taechakraichana N. Osteoporosis in different age-groups and various body mass index (BMI) ranges in women undergoing bone mass measurement at King Chulalongkorn Memorial Hospital. J Med Assoc Thailand. 2012;95(5):644-649. 
50. Cummings SR. Appendicular bone density and age predict hip fracture in women. The Study of Osteoporotic Fractures Research Group. JAMA. 1990;263(5):665-668. doi:10.1001/jama.1990.03440050059033

51. Majumdar S, Genant HK, Grampp S, et al. Correlation of trabecular bone structure with age, bone mineral density, and osteoporotic status: in vivo studies in the distal radius using high resolution magnetic resonance imaging. J Bone Mineral Res. 1997;12 (1):111-118. doi:10.1359/jbmr.1997.12.1.111

52. Tang Y, Gong L, Chen X, et al. Age-related changes in body composition and bone mineral density and their relationship with the duration of diabetes and glycaemic control in type 2 diabetes. Diabetes Metab Syndr Obes. 2020;13:4699-4710. doi:10.2147/dmso.S278425

53. Jiang Y, Zhang Y, Jin M, et al. Aged-related changes in body composition and association between body composition with bone mass density by body mass index in Chinese Han men over 50-year-old. PLoS One. 2015;10(6):e0130400. doi:10.1371/journal.pone.0130400

54. Jing Y, Hong T, Bi Y, et al. Prevalence, treatment patterns and control rates of metabolic syndrome in a Chinese diabetic population: China Cardiometabolic Registries 3B study. J Diabetes Investig. 2018;9 (4):789-798. doi:10.1111/jdi.12785
55. Catalano A, Morabito N, Di Vieste G, et al. Phalangeal quantitative ultrasound and metabolic control in pre-menopausal women with type 1 diabetes mellitus. J Endocrinol Invest. 2013;36(5):347. doi:10.3275/8646

56. Holloway-Kew KL, Betson A, Rufus-Membere PG, et al. Impact microindentation in men with impaired fasting glucose and type 2 diabetes. Bone. 2021;142:115685. doi:10.1016/j.bone.2020.115685

57. Lui DT, Lee $\mathrm{CH}$, Chau VW, et al. Potential role of fibroblast growth factor 21 in the deterioration of bone quality in impaired glucose tolerance. J Endocrinol Invest. 2021;44(3):523-530. doi:10.1007/ s40618-020-01337-y

58. Kodama K, Tojjar D, Yamada S, et al. Ethnic differences in the relationship between insulin sensitivity and insulin response: a systematic review and meta-analysis. Diabetes Care. 2013;36 (6):1789-1796. doi:10.2337/dc12-1235

Diabetes, Metabolic Syndrome and Obesity: Targets and Therapy

Dovepress

\section{Publish your work in this journal}

Diabetes, Metabolic Syndrome and Obesity: Targets and Therapy is an international, peer-reviewed open-access journal committed to the rapid publication of the latest laboratory and clinical findings in the fields of diabetes, metabolic syndrome and obesity research. Original research, review, case reports, hypothesis formation, expert opinion and commentaries are all considered for publication. The manuscript management system is completely online and includes a very quick and fair peer-review system, which is all easy to use. Visit http://www.dovepress.com/testimonials.php to read real quotes from published authors.

Submit your manuscript here: https://www.dovepress.com/diabetes-metabolic-syndrome-and-obesity-targets-and-therapy-journal 